\title{
DESAIN DASHBOARD UNTUK PENDUKUNG SISTEM CERDAS ANALISIS KESESUAIAN KEBUTUHAN DAN KETERSEDIAAN SUMBERDAYA PEMBANGUNAN DESA MANDIRI
}

\author{
Dedi Trisnawarman ${ }^{1}$, Zyad Rusdi $^{2}$ \\ ${ }^{1,2}$ Program Studi Sistem Informasi, Fakultas Teknologi Informasi, Universitas Tarumanagara, \\ Jln. Letjen S. Parman No. 1, Jakarta, 11440, Indonesia

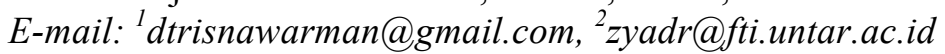

\begin{abstract}
Abstrak
Tujuan dari penulisan makalah ini adalah perancangan dashboard dari suatu sistem cerdas untuk membantu pengambilan keputusan pembangunan desa. Model yang diusulkan terdiri dari dua bagian yaitu model penilaian kesesuaian kebutuhan dan ketersediaan sumberdaya (MPK3S) dan model evaluasi dan monitoring kinerja. Data yang diperoleh baik data primer maupun data skunder diintegrasikan dalam bentuk pemodelan data untuk analisis multidimensional yaitu data warehouse dan proses ETL (Extract, Transform and Load). Metode yang digunakan dalam model pertama (MPK3S) adalah gabungan /hybrid beberapa metode MCDA (Multi Criteria Decision Making) seperti AHP (Analitical Hierarcy Process), electre, serta algoritma cerdas data mining untuk klasifikasi dan prediktif. Penelitian ini menghasilkan suatu model evaluasi dan monitoring kinerja menggunakan metode perhitungan KPI (key perfomance indicator) dan Perfomance Prism dalam aplikasi digital dashboard. Hasil akhir dari penelitian adalah sebuah aplikasi sistem cerdas yang mampu membantu dalam pengambilan keputusan untuk menentukan prioritas masalah pembangunan desa, menentukan alternatif solusi masalah pembangunan dan melakukan monitoring serta evaluasi kinerja.
\end{abstract}

Kata kunci : cerdas, dashboard, desa, pembangunan, sistem

\begin{abstract}
The purpose of writing this paper is to design the dashboard of an intelligent system to assist village development decision. The proposed model consists of two parts: the conformity assessment model of needs and resource availability (MPK3S) and evaluation model and performance monitoring. Data obtained both primary and secondary data are integrated in the form of data modeling for multidimensional analysis ie data warehouse and ETL process (Extract, Transform and Load). The method used in the first model (MPK3S) is a hybrid of several MCDA (Multi Criteria Decision Making) methods such as AHP (Analitical Hierarcy Process), electre, and intelligent data mining algorithms for classification and predictive. This research produces a model of evaluation and performance monitoring using KPI calculation method (key perfomance indicator) and Perfomance Prism in digital dashboard application. The final result of the research is an intelligent system application capable of assisting in decision making to determine priority of village development problem, determining alternative solution of development problem and doing monitoring and performance evaluation
\end{abstract}

Keywords: smart, dashboard, village, development, system 


\section{PENDAHULUAN}

Pentingnya pembangunan yang menyentuh desa serta aspek kehidupan masyarakatnya, menempatkan pemerintah dengan kewajibannya untuk melaksanakan pembangunan di tingkat desa. Oleh karena itu, pembangunan desa harus dilakukan dengan baik serta menyentuh kebutuhan riil masyarakat, sehingga pembangunan di desa dapat menyentuh langsung dengan masyarakatnya. Maka dari itu pembangunan desa harus terencana dengan baik berdasarkan hasil kajian dan analisis yang menyeluruh terhadap segala macam potensi dan permasalahan yang kemungkinan akan dihadapi. Hasil analisis tersebut dijadikan dasar pertimbangan dalam perencanaan dan program pembangunan desa di masa mendatang dengan melibatkan partisipasi masyarakat secara maksimal.

Kebutuhan aplikasi dan sistem informasi bagi organisasi modern merupakan tuntutan yang harus dipenuhi dalam era globalisasi dan abad informasi yang menuntut kecepatan dan keterhubungan satu sama lain tanpa dibatasi tempat dan waktu. Basisdata merupakan salah satu komponen terpenting dalam mewujudkan aplikasi sistem informasi, dan masing-masing organisasi memiliki model basisdata yang spesifik yang harus sesuai dengan proses bisnis masing-masing organisasi. Pemerintahan Desa merupakan organisasi pemerintahan terkecil yang merupakan ujung tombak pembangunan nasional. Dengan diterapkannya Undang Undang Desa No 6 tahun 2014, maka Pemerintahan Desa memiliki sumberdaya keuangan dan kemandirian untuk mewujudkan keberhasilan pembangunan dengan memaksimalkan semua potensi desa. Oleh karena itu dibutuhkan model basisdata yang terintegrasi untuk mendukung proses pembangunan tersebut.

Konsep pembangunan desa mandiri membutuhkan perencanaan dan penilaian kesesuaian terhadap kebutuhan dan sumberdaya yang tersedia, sehingga tujuan pembangunan dapat tercapai sesuai dengan harapan masyarakat. Begitu juga penilaian terhadap pekerjaan yang sudah dilakukan perlu dievaluasi untuk perbaikan penyempurnaan perencanaan pembangunan berikutnya. Teknologi informasi dan algoritma cerdas yang tersedia menyediakan kemampuan untuk membantu pengambilan keputusan, baik untuk penilaian kesesuain dan penilaian terhadap evaluasi kinerja. Berangkat dari rumusan masalah tersebut maka penelitian ini dimaksudkan untuk membangun sebuah desain dashboard yang dapat digunakan untuk membantu penilaian kesesuaian kebutuhan dan ketersediaan sumberdaya dalam pembangunan desa mandiri.

\section{METODE PENELITIAN}

\subsection{Information Dashboard}

Information dashboard adalah alat untuk menyajikan informasi secara sekilas, solusi bagi kebutuhan informasi organisasi yang memberikan tampilan antarmuka degan berbagai bentuk seperti diagram, laporan, indicator visual, mekanisme alert, yang dipadukan dengan informasi yang dinamis dan relevan [1]. Tujuan penggunaan information dashboard yaitu untuk mengukur kinerja, memonitor proses yang sedang berjalan, dan memprediksi kondisi di masa mendatang. Sedangkan (Novell, 2004) dalam penelitiannya membagi 4 (empat) kriteria utama yang harus dimiliki oleh dashboard, yaitu mengkonsolidasikan informasi bisnis yang relevan dan menyajikan dalam satu kesatuan pandangan, informasi yang disampaikan harus akurat secara tepat waktu, memberikan akses yang aman terhadap informasi yang sensitif [2].

Beberapa prinsip mendasar yang dijadikan sebagai landasan dalam merancang metodologi pembangunan dashboard. Prinsip-prinsip tersebut adalah dashboard: Menyajikan informasi mengenai KPI dengan tujuan yang spesifik, mensinergikan informasi dari berbagai aspek dalam layar tunggal, merupakan alat yang responsif dan interaktif dengan penggunanya, 
memungkinkan tiga hal sekaligus yaitu analisis kondisi sebelumnya, memonitor kondisi saat ini, dan memprediksi tren kedepan, memiliki faktor personalisasi [1]. Setiap bagian dalam organisasi memiliki dashboardnya sendiri, memungkinkan kolaborasi dan komunikasi antar bagian dalam organisasi. Keenam prinsip tersebut digunakan sebagai dasar dalam melakukan perancangan metodologi pembangunan dashboard.

\subsection{Key Performance Indikator (KPI) dan Perfomace Prism}

Definisi KPI merujuk pada definisi yang dirumuskan dalam "Performance Indicator Resource Catalogue" yang diterbitkan oleh Australian Government, Department of Finance and administration (2006), adalah ukuran spesifik tentang kinerja organisasi dalam wilayah bisnisnya.

Beberapa penelitian tentang KPI telah banyak dilakukan, diantaranya tentang metode pengukuran KPI seperti yang dilakukan oleh Neely dan Adam (2000). Ukuran tersebut dapat berupa financial dan non-financial yang dapat digunakan untuk mengukur kinerja strategis organisasi. Sebagai alat ukur kinerja strategis organisasi, KPI dapat mengindikasikan kesehatan dan perkembangan organisasi, dan atau keberhasilan kegiatan, program atau penyampaian pelayanan untuk mewujudkan target-target atau sasaran organisasi [3]. Vanany dan Tanukhidah (2002) melakukan penelitian mengenai perancangan dan implementasi sistem pengukuran kinerja dengan metode performance prism untuk mengetahui kinerja hotel sebagai obyek [4]. Mardiono dkk. (2011), melakukan penelitian mengenai pengukuran kinerja menggunakan model performance prism di perusahaan makanan, dalam penelitian tersebut digunakan metode SWOT untuk memetakan model Performance Prism yang mempunyai lima perspektif, yaitu Stakeholder Satisfaction, Strategy, Process, Capabilities dan Stakeholder Contribution [5]. Schiavo-Campo (1999) dalam Asropi (2007) juga menguraikan kriteria-kriteria yang harus dipenuhi oleh KPI, yang kemudian dirumuskannya dalam akronim "CREAM", yaitu clear, relevant, economic, adequate dan monitorable [6].

Kriteria-kriteria tersebut diatas adalah alat bantu yang efektive untuk memilih KPI. Indikator kinerja yang memenuhi kriteria tersebut, sudah barang tentu akan menjadi alat ukur yang memadai untuk mengukur perkembangan pencapaian tujuan organisasi. Adapun indikator kinerja yang tidak memenuhi keseluruhan kriteria tersebut, lebih baik tidak dijadikan KPI bahkan tidak perlu digunakan sebagai indikator kinerja [6]. Vanany dan Tanukhidah (2002) dalam penelitiannya menggunakan metode Objective Matrix (OMAX) untuk melakukan Scoring terhadap KPI. Metode ini mengkombinasikan pendekatan kuantitatif dan kualitatif [4]. Dapat digunakan untuk mengukur aspek kinerja yang dipertimbangkan dalam suatu unit kerja. Indikator untuk setiap input dan output dapat didefinisikan dengan jelas. Menyertakan pertimbangan pihak manajemen dalam penentuan skor sehingga terkesan lebih fleksibel. Konsep dari pengukuran ini yaitu penggabungan beberapa kriteria kinerja kelompok kerja kedalam sebuah matrik. Setiap kriteria kinerja memiliki sasaran berupa jalur khusus untuk perbaikan serta memiliki bobot sesuai dengan kepentingan terhadap tujuan organisasi. Hasil akhir dari pengukuran dengan metode OMAX ini adalah sebuah nilai tungal untuk suatu kelompok kerja.

\section{HASIL DAN PEMBAHASAN}

Penelitian ini ditujukan untuk melakukan penilaian evaluasi terhadap program pembangunan yang sudah dilaksanakan atau yang sedang berlangsung. Evaluasi mencakup monitoring terhadap proses program pembangunan yang sedang berlangsung, evaluasi terhadap kinerja atau target program pembangunan dan prediksi terhadap program selanjutnya yang akan dijalankan. 
Langkah awal yang dilakukan adalah menentukan indikator atau kriteria evaluasi berdasarkan data dan masukan yang diperoleh pada penelitian tahap pertama, langkah berikutnya adalah menetukan metode evaluasi yaitu metode Performance Prism dan Key Perfomance Indicator (KPI) dengan scoring menggunakan metode Objective Matrixs (OMAX)

\subsection{Desain Arsitektur Data Warehouse}

Arsitektur data warehouse yang akan dirancang adalah aristektur data warehouse terpusat (centralized). Alasan memilih arsitektur data warehouse terpusat, yaitu :

- Data yang terdapat dalam data warehouse memiliki data yang terintegrasi dengan baik.

- Pemeliharaan data lebih mudah karena semua data terdapat dalam satu data warehouse.

Dalam rancangan ini, data internal maupun eksternal akan ditampung ke dalam satu wadah data warehouse sehingga user akan mudah untuk mengelolah data seperti melakukan pencarian data yang diperlukan. Gambar 1 menunjukan rancangan arsitektur data warehouse yang dibuat :

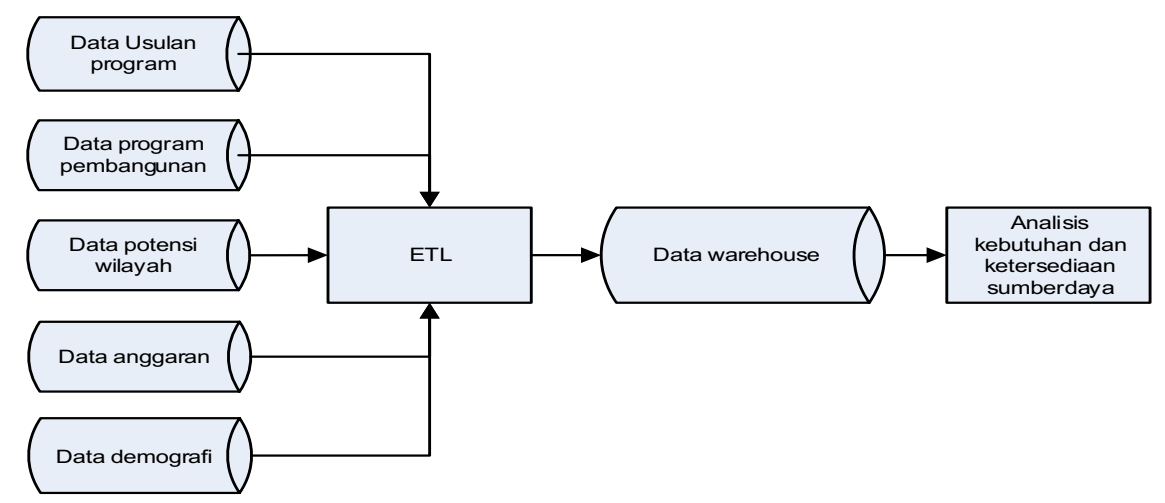

Gambar 1. Arsitektur Data Warehouse analisis kebutuhan dan ketersediaan sumberdaya

Data kependudukan/demografi adalah data tentang penduduk seperti nama, alamat, pekerjaan, usia, jenis kelamin dan alin sebagainya. Data potensi adalah data tentang wilayah dan potensi yang dimiliki seperti luas daerah, posisi, sumberdaya alam yang dimiliki dan lain sebagainya. Data program pembangunan adalah catatan tentang pembangunan baik pembangunan yang telah dilakukan maupun yang masih dalam tahap perencanaan. Data anggaran adalah data tentang jumlah anggaran yang dimiliki, sumber anggaran, penggunaan anggaran dan lain sebagainya. Data pemetaan masalah adalah data yang diperoleh dari masyarakat dan survey dilapangan yang berhubungan dengan permasalahan program pembangunan desa, seperti masalah infrastruktur, kesehatan, pendidikan dan lain sebagainya. Dari data tersebut akan dilakukan proses ETL (Extract, Transform, Loading) yang kemudian hasilnya akan disimpan ke dalam data warehouse.

Desain data warehouse terdiri desain skema bintang yang terdiri dari tabel fakta, tabel dimensi, meta data dan proses ETL. Desain tabel fakta terdiri dari tabel fakta Analisis Kegiatan, tabel fakta Analisis Penduduk, tabel fakta Analisis Usulan. dan tabel fakta Analisis Potensi sedangkan tabel dimensi terdiri dari dim_time, dim_staf, dim_wilayah, dim_usulan, dim_anggaran, dim_potensi.

Gambar 2. adalah gambar skema bintang yang menjelaskan tentang analisis kegiatan, jumlah kegiatan dan jumlah anggaran adalah atribut yang dianalisis dengan dimensi waktu, dimensi kegiatan, dimensi anggaran dan dimensi wilayah. Dari analisis tabel ini dapat diketahui berapa jumlah kegiatan dan jumlah anggaran yang berhubungan dengan waktu kegiatan, dan wilayah dimana kegiatan tersebut diadakan. 


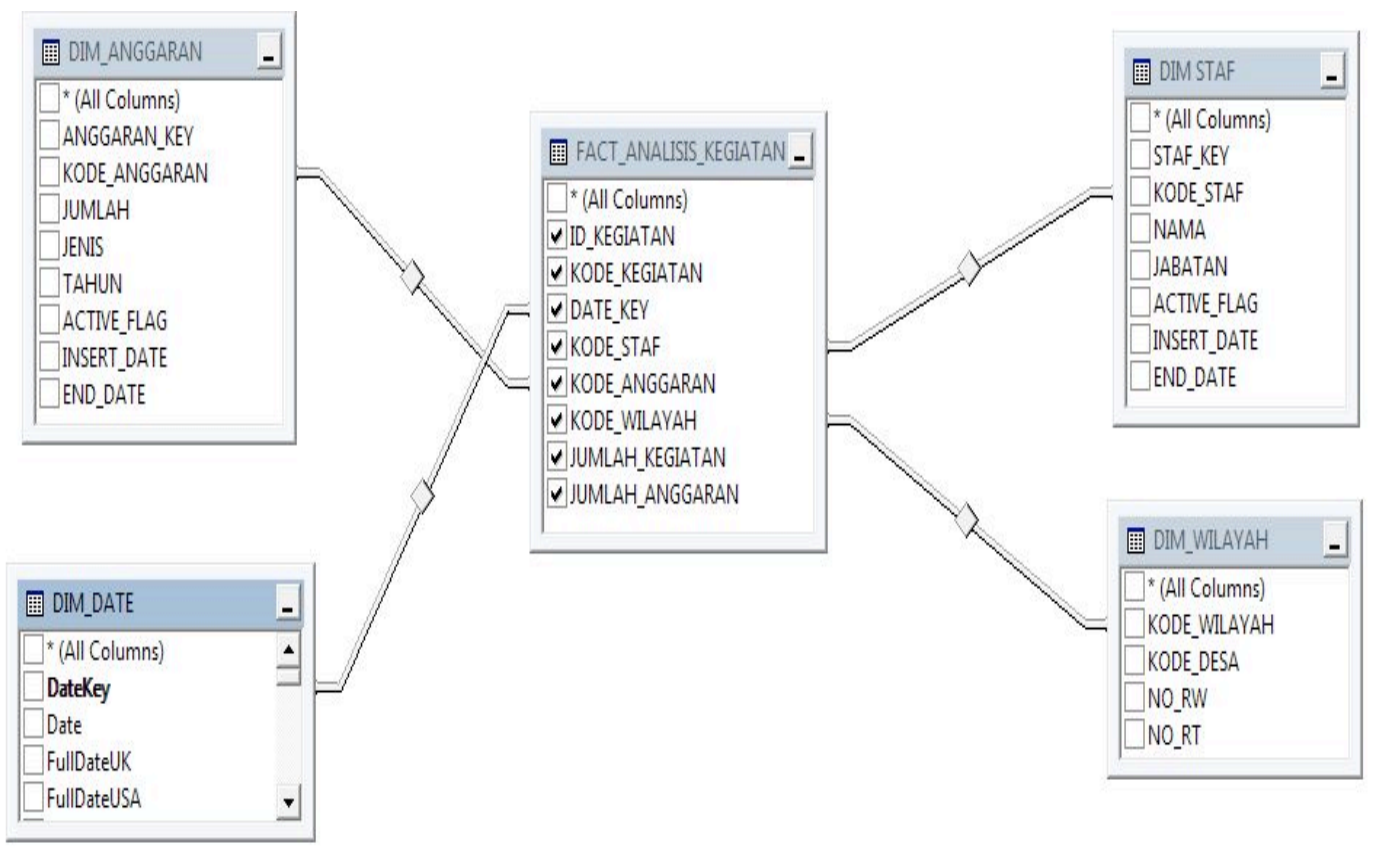

Gambar 2. Skema Bintang Analisis Kegiatan

Gambar 3, adalah gambar skema bintang yang menjelaskan tentang analisis usulan atau partisipasi dari masyarakat, yang dapat dihubungkan dengan profil pengusul, kegiatan yang diusulkan dan waktu.

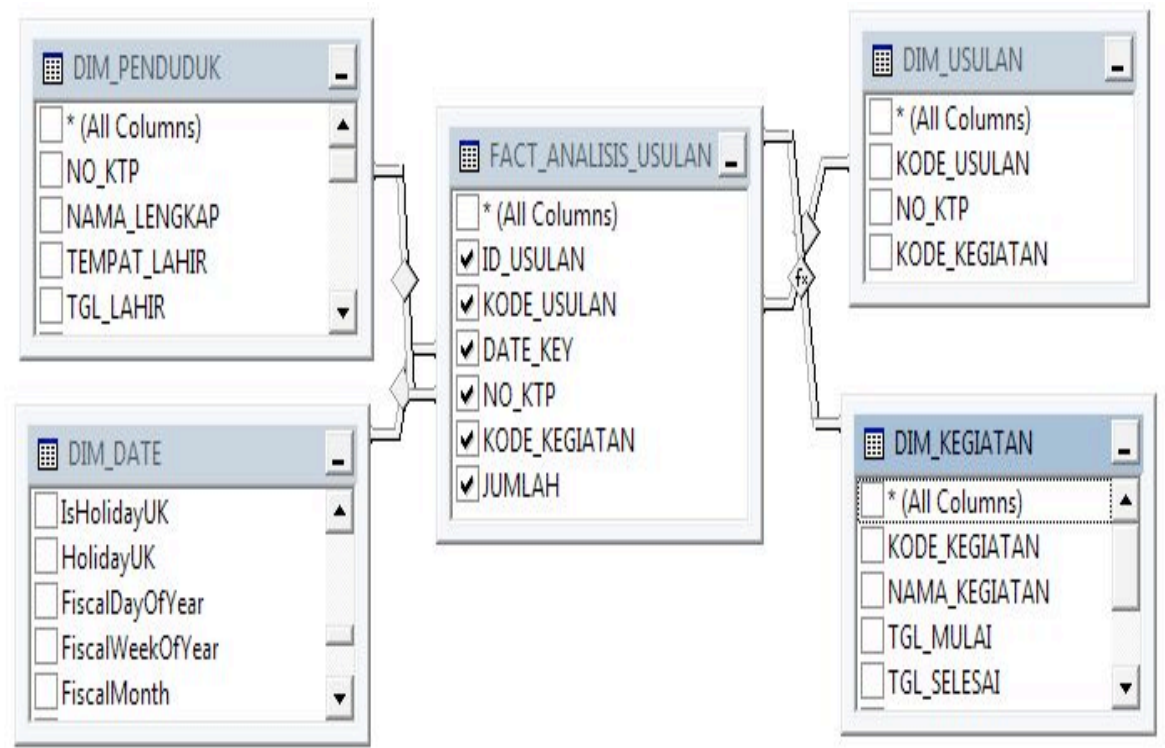

Gambar 3.Skema Bintang Analisis Usulan

Gambar 4, bertujuan agar dapat digunakan untuk menganalisis jumlah potensi sumberdaya yang tersedia, yang dapat digunakan dalam pembangunan desa. Analisis jumlah potensi sumber daya tersebut dapat dihubungkan dengan wilayah dan waktu. 


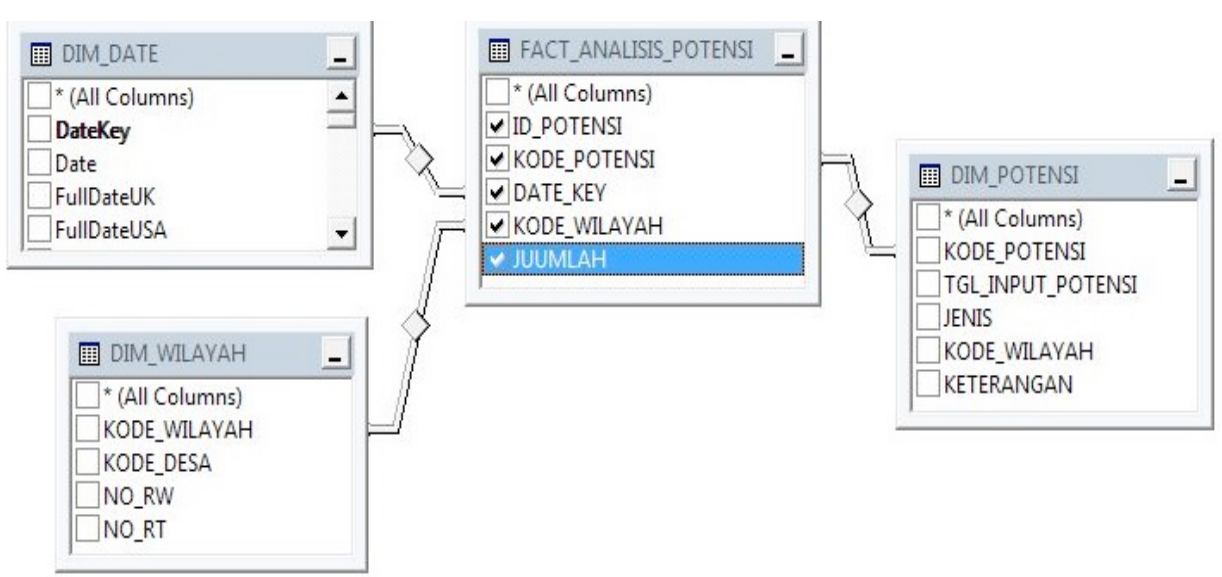

Gambar 4. Skema Bintang Analisis Potensi

Gambar 5, bertujuan agar dapat digunakan untuk menganalisis profil pengusul, berdasarkan data demografi penduduk.

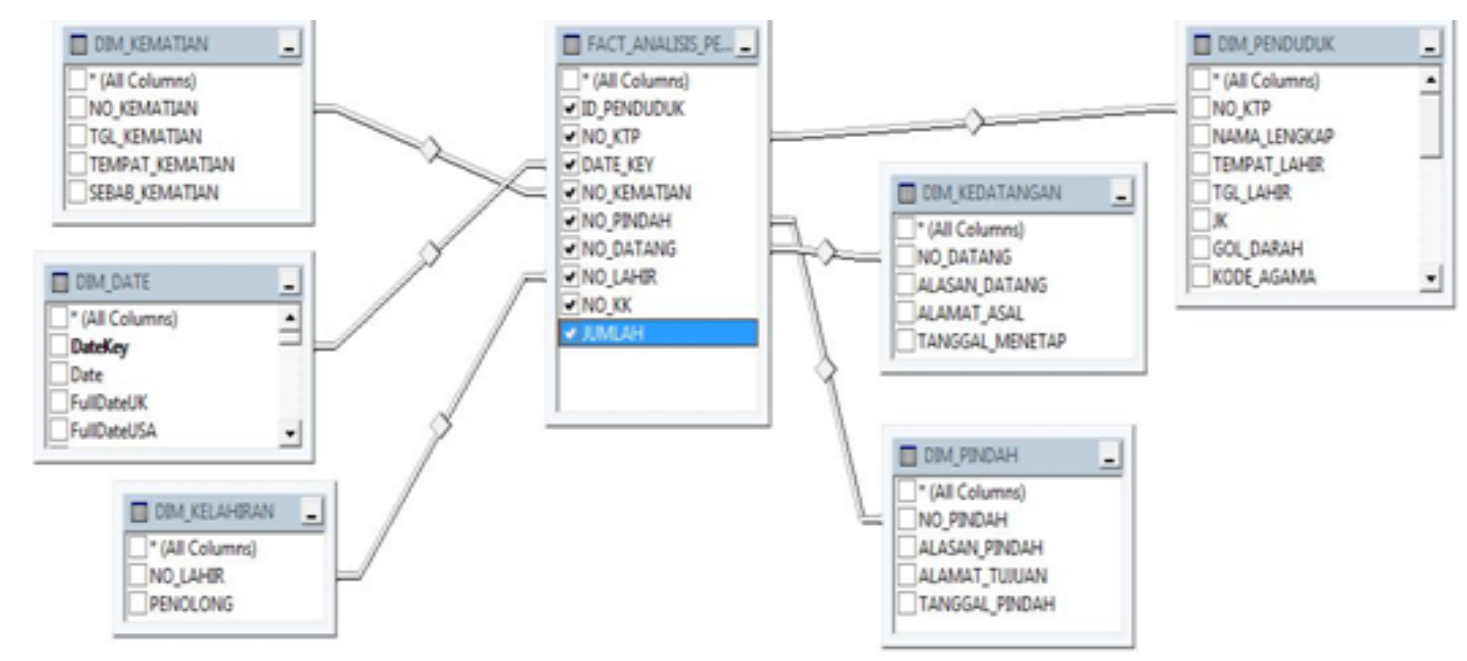

Gambar 5 Tabel Fakta Analisis Penduduk

Semua tabel fakta untuk analisis dihubungkan dengan tabel dimensi sesuai dengan kebutuhan analisis. Untuk kebutuhan analisis tersebut diperlukan tiga proses yang terdiri dari proses tabel dimensi, proses tabel fakta dan proses stagging.

\subsection{Desain Dashboard}

Desain dashboard ditujukan untuk model pengambilan keputusan, melalui analisis tampilan multidimensinal. Untuk mendapatkan tampilan yang mendukung analisis multidimensional perlu dirumuskan key perfomance indikator yang merupakan ukuran bagi faktor-faktor yang dianggap kritis atau critical success factors.

\subsection{Rumusan key perfomance indicator}

Tahap identifikasi dan rumusan KPI diawali dengan model Performance Prism dengan mengidentifikasi strategi perusahaan melalui penjabaran visi dan misi organisasi yaitu Pemerintahan Desa Sumbersari. Selanjutnya mengindentifikasi siapa stakeholder yang terlibat dalam sistem pengambilan keputusan penentuan program pembangunan desa, dan selanjutnya mengetahui apa yang menyebabkan stakeholder puas sampai langkah terakhir mendetailkannya 
dalam bentuk KPI. Hasil identifikasi menunjukkan bahwa ada 3 stakeholder yang terlibat yaitu, penduduk desa, pemerintah desa, dan pemerintahan supra desa (Kabupaten). Namun karena stakeholder pemerintah supra desa (Kabupaten) tidak terlibat secara langsung maka dapat diabaikan. Maka dari itu stakeholder yang nantinya akan dipertimbangkan dalam penentuan KPI adalah penduduk desa dan pemerintah desa.

Stakeholder yang ada perlu diketahui apa yang menyebabkan mereka puas dan kontribusi apa yang seharusnya diberikan oleh masing-masing stakeholder tersebut terhadap perusahaan. Hasil ini akan menghasilkan kepuasan (satisfaction) stakeholder dan kontribusi (contribution) stakeholder. Setelah itu selanjutnya adalah mendapatkan KPI yang sesuai guna kepentingan pengukuran kinerja terhadap permasalahan pembangunan desa. Penyusunan success map dilakukan pada setiap stakeholder untuk menggambarkan alur kelima perspektif ini, seperti pada Gambar 6, 7 dan 8 .

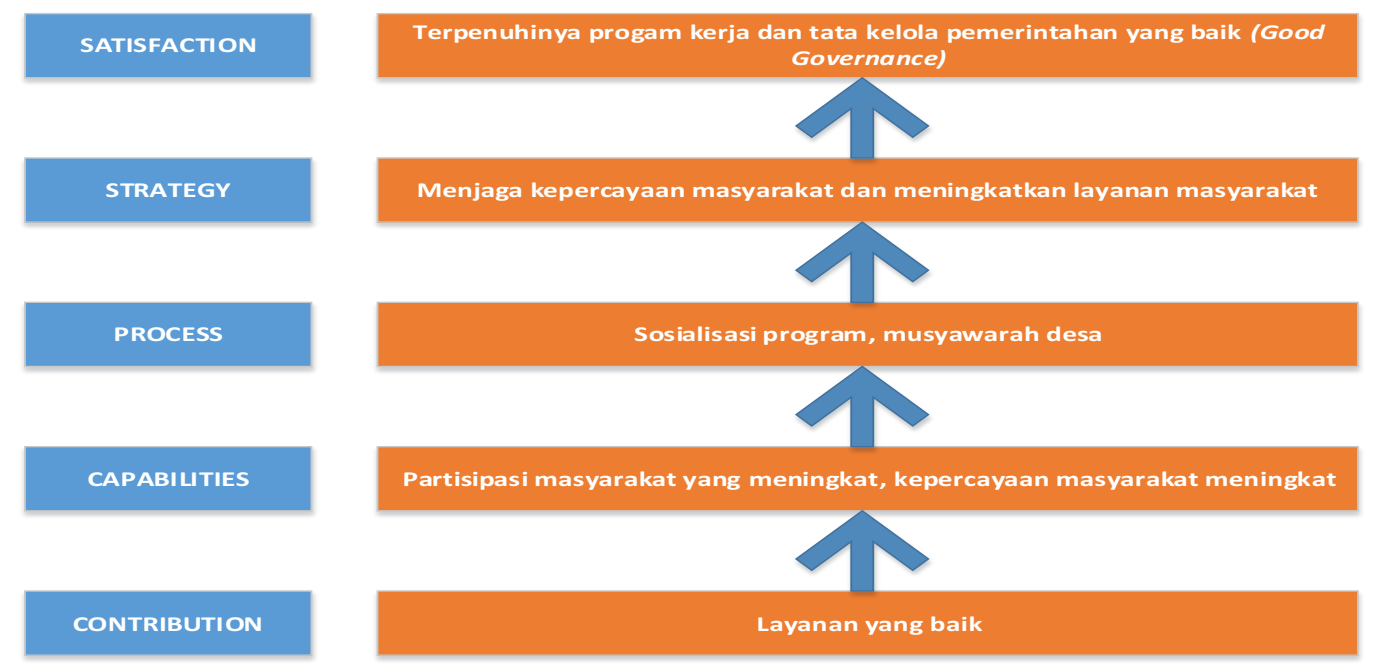

Gambar 6. Success Map hubungan indikator pengukuran kinerja antar-perspektif Performance Prism pada stakeholder pemerintah desa

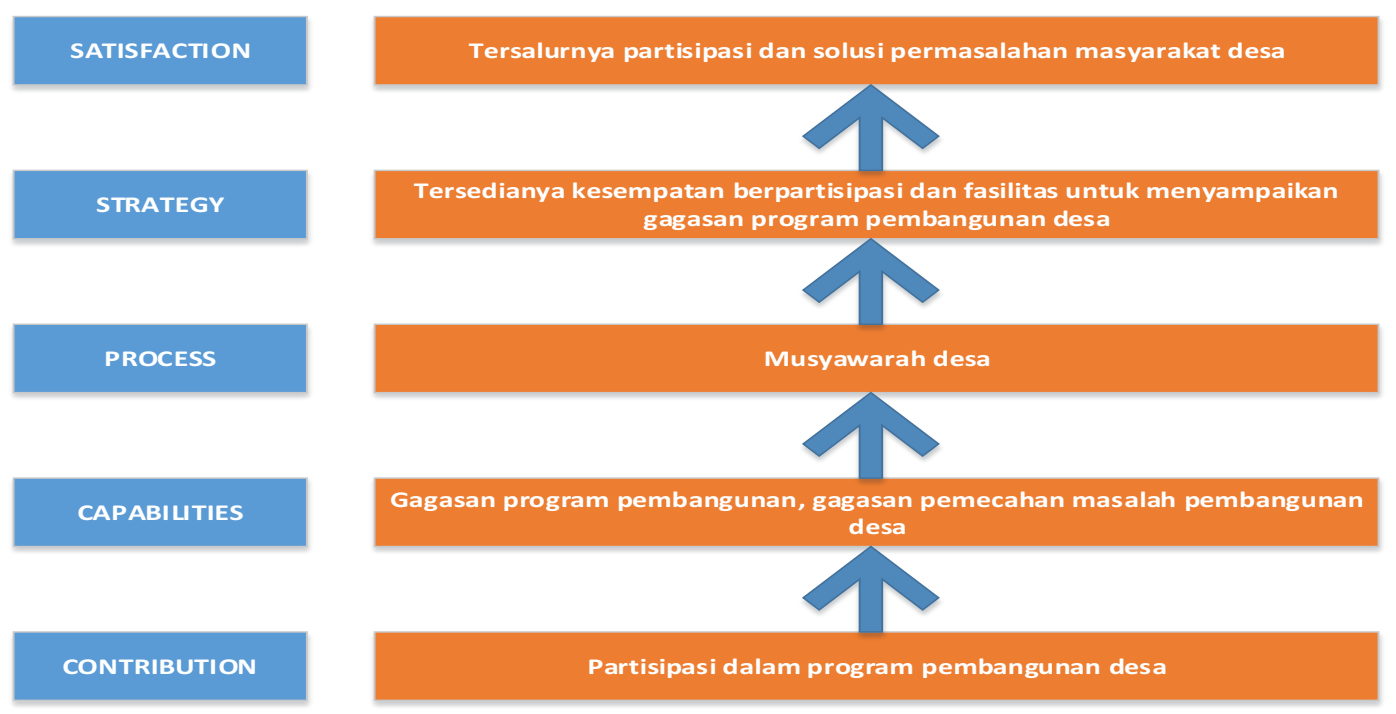

Gambar 7. Success Map hubungan indikator pengukuran kinerja antar-perspektif Performance Prism pada stakeholder penduduk desa 


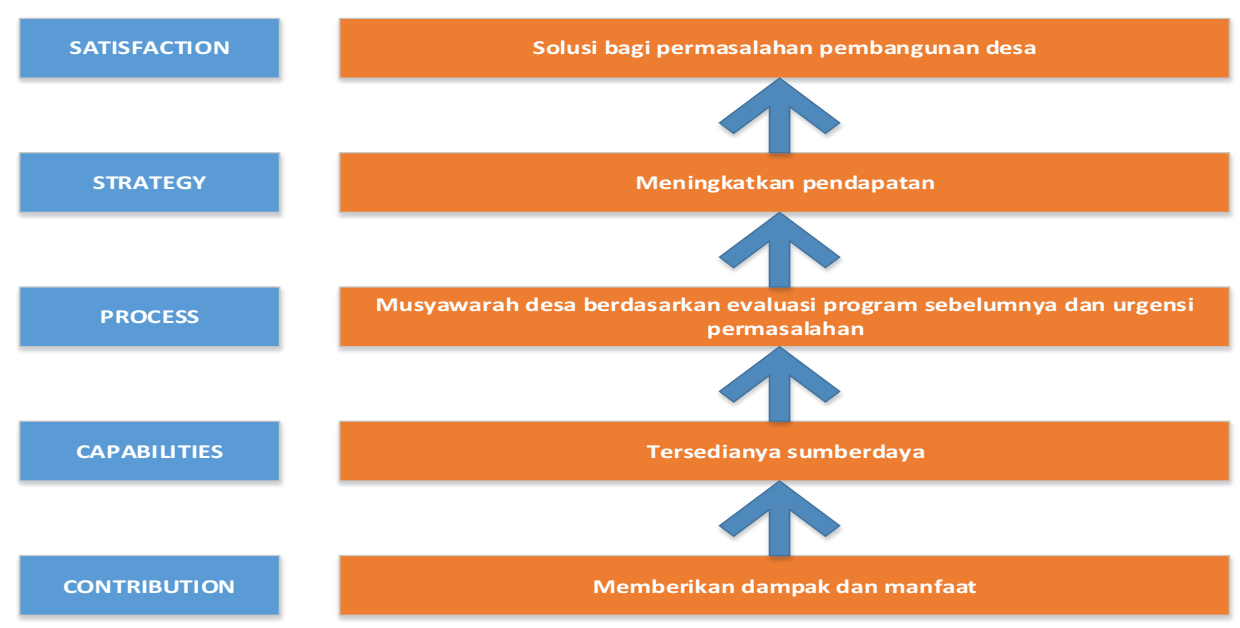

Gambar 8. Success Map hubungan indikator pengukuran kinerja antar-perspektif Performance Prism pada kriteria prioritas pembangunan

\section{KESIMPULAN}

Kesimpulan penelitian ini adalah sebagai berikut:

1. Penelitian ini dapat merumuskan key perfomance indikator (KPI) untuk analisis kebutuhan dan ketersediaan sumberdaya dalam pembangunan desa

2. KPI yang dirumuskan sesuai dengan kriteria untuk menentukan prioritas masalah pembangunan desa yang telah dirumuskan dalam penelitian tahap pertama yaitu: tingkat kebutuhan mendesak, tingkat dampak atau manfaat, sumber daya yang tersedia, berdasarkan evaluasi program sebelumnya, masalah sering berulang

3. Desain dashboard yang akan dibangun sesuai dengan model data yang dibangun dan KPI yang dirumuskan

\section{DAFTAR PUSTAKA}

[1] Harianti, E. 2008. Pengembangan Metodologi Pembangunan Information Dashboard Untuk Monitoring Kinerja Organisasi. e-Indonesia Initiative 2008 (eII2008) Konferensi dan Temu Nasional Teknologi Informasi dan Komunikasi untuk Indonesia 21-23 Mei 2008, Jakarta

[2] Novell, 2004 Secure Enterprise Dashboard: A Key To Business Agility (White Paper),

[3] Neely, A.D., and Adams, C.A, 2000. Perspectives on Performance: The Performance Prism, The Evolution of Business Performance Measurement Systems, EPSRC, Cranfield School of Management, UK

[4] Iwan Vanany dan Dian Tanukhidah, 2004, Perancangan Dan Implementasi Sistem Pengukuran Kinerja Dengan Metode Performance Prism, Jurnal Teknik Industri Vol. 6, No. 2, Desember 2004: 148 - 155 , Institut Teknologi Sepuluh Nopember, Surabaya

[5] Mardiono dkk. 2011. Pengukuran Kinerja Menggunakan Model Perfomance Prism (Studi Kasus di Perusahaan Makanan). Proceeding 6th National Industrial Engineering Conference (NIEC-6), Surabaya.

[6] Asropi, 2007, Membangun Key Performance Indicator Lembaga Pelayanan Publik, Manajemen Pembangunan, Nomor 57/I/Tahun XVI.

[7] Asghar. S, Fong S., Hussain T., 2009. Business Intelligence Modeling: A Case Study of Disaster Management Organization in Pakistan, 2009 Fourth International Conference 
on Computer Sciences and Convergence Information Technology

[8] Baars H., Kemper H.G, Lasi H., Siegel M., 2008. Combining RFID Technology and Business Intelligence forSupply Chain Optimization - Scenarios for Retail Logistics, Proceedings of the 41st Hawaii International Conference on System Sciences

[9] Bakshi, T., Sinharay, A., \& Sarkar, B., 2011. Exploratory Analysis of Project Selection through MCDM. ICOQM-10, 128-131.

[10] Dayal U., Castellanos M., Simitsis A., Wilkinson K., 2009. Data Integration Flows for Business Intelligence, EDBT'09, March 24-26, 2009, Saint Petersburg, Russia.

[11] Deng, H., \& Wibowo, S., 2008. Intelligent Decision Support for Evaluating and Selecting Information Systems Projects, The International Association of Engineers (IAENG), (August).

[12] Ernawati, 2012. Penentuan Skala Prioritas Pembangunan Waduk di Jawa Barat, Jurnal Sosioteknologi Edisi 25 Tahun 11, April

[13] Fiati R., dan N.Latifah, 2013. Sistem Pendukung Keputusan untuk Menentukan Kelayakan Desa Mandiri Menggunakan FMADM, Prosiding Seminar Nasional Ilmu Komputer FMIPA Unnes, 23 November

[14] Hartati S., Nugroho A., 2012. Sistem Pendukung Keputusan Berbasis AHP (Analytical Hierarchy Process) Untuk Penentuan Kesesuaian Penggunaan Lahan (Studi Kasus : Kabupaten Semarang). Jurnal Teknologi Technoscientia ISSN: 1979-8415 Vol. 5 No. 1 Agustus

[15] Hoshino H., Zhong N, 2007. Dynamic Hybrid Type Mining in an Intelligent eGovernment Model, IEEE/WIC/ACM International Conferences on Web Intelligence and Intelligent Agent Technology - Workshops

[16] Ismaili, H., 2013. Multi-Criteria Decision Support for Strategic Program Prioritization at Defence Research and Development Canada, University of Ottawa.

[17] Kocbek A.,, Juric M.B., 2010. Using Advanced Business Intelligence Methods In Business Process Management-Conference on Data Mining and Data Warehouses. SiKDD 12 October, Ljubljana, Slovenia

[18] Khastar H., Khalouei G.A., Kalhorian R., Maleki M., 2011. Policy Intelligence as an Administrative System for Monitoring Public Field, International Conference on Sociality and Economics DevelopmentIPEDR vol.10 IACSIT Press, Singapore

[19] Kazemi, S. M., Kazemi, S. M. M., \& Bahri, M., 2011. Six Sigma project selections by using a Multi Criteria Decision making approach: a Case study in Poly Acryl Corp, Proceedings of the 41 st International Conference on Computers \& Industrial Engineering (pp. 502-507).

[20] Siwastiono S., 2006. Prospek Pengembangan Desa, Fokus Media, Bandung : Hal. 13

[21] Siregar, B.B., 2001. Menelusuri Jejak Ketertinggalan Merajut Kerukunan Melintasi Krisis. Jakarta : Pusat P3R-YAE.

[22] SPosayanant S., Chareonngam C., 2009. Prototype KPIs for rural infrastructure development The practice of sub-district local governments, International Journal of Productivity and Performance Management Vol. 59 No. 8, 2010 pp. 717-733 q Emerald Group Publishing Limited 1741-0401

[23] Undang-Undang Republik Indonesia Nomor 6 Tahun 2014

[24] Yushu Y., Fulin W., Jie Z., 2009. Intelligent fertilization Decision Support System Based On Knowledge Model and WebGIS Decision For Fertilization, IEEE 